\title{
EFEKTIVITAS FUNGI MIKORIZA ARBUSKULA INDIGENOUS TERHADAP PERTUMBUHAN STEK PUCUK GOSALE (Syzygium malaccense (L.) Merr \& L.M Perry)
}

\author{
Effectiveness of Indigenous Arbuscular Mycorrhizal Fungi to the Shoot Cutting Growth of \\ Gosale (Syzygium malaccense (L.) Merr \& L.M Perry)
}

Steffani Silferansti Tak ${ }^{*}$, Irdika Mansur ${ }^{2}$, Prijanto Pamoengkas ${ }^{2}$

(Diterima Juli 2017/Disetujui September 2017)

\begin{abstract}
Gosale (Syzygium malaccense (L.) Merr. \& L.M.Perry) that belongs to the Myrtaceae family is one of the leading local plant species grown in Halmahera, North Maluku. Some problems in gosale breeding such as limited seed availability, low seed production due to seasonal fruiting and the nature of seeds that can not be stored for a long period (recalcitrant), suggest an alternative new production technique through a vegetative propagation (shoot cutting). Moreover, Improved seedling quality can be attempted by AMF inoculation, in which AMF at shoot cuttings play a role in initiating the formation of adventive roots. This study was conducted for 9 months using completely randomized design (CRD) with indigenous AMF inoculation treatment. The results showed that gosale cuttings that planted with indigenous AMF inoculation were effective at all observed variables. Inoculum AMF inoculated without the addition of host plant Pueria javanica at gosale shoot cuttings suggested the best treatment. The treatment of inoculum AMF from Kusumadehe (M1) obtained the best result in the variable of plant height increase, dry weight of shoot, dry weight of root, root shoot ratio), and seedling quality index. While the treatment of Inoculum AMF from Soakonora revealed the highest result in the variable of plant diameter increase and AMF colonization.
\end{abstract}

Keywords: gosale, shoot cuttings, AMF, Pueraria javanica, West Halmahera

\section{PENDAHULUAN}

Gosale (Syzygium malaccense (L.) Merr. \& L.M.Perry) termasuk family Myrtaceae merupakan salah satu jenis tanaman unggulan lokal yang tumbuh di Halmahera, Maluku Utara. Tanaman tersebut banyak dimanfaatkan masyarakat untuk industri produk jadi seperti papan, lata, dan balok (BPTH Maluku-Papua 2010). Teknologi budidaya gosale secara ilmiah masih belum banyak dikaji sehingga perlu dilakukan penelitian untuk memperoleh teknologi budidaya khususnya untuk penyediaan bibit. Pada umumnya pengadaan bibit gosale hanya mengharapkan bibit yang tersedia dibawah tegakan gosale di alam. Permasalahan dalam pembibitan gosale ialah ketersediaan benih yang terbatas, produksi benih yang rendah karena tergantung musim berbuah dan sifat benih yang tidak bisa disimpan lama (BPTH MalukuPapua). Sementara saat ini keberadaan pohon induk penghasil benih telah mengalami penurunan sehingga diperlukan teknik pembibitan alternatif yang tidak

\footnotetext{
${ }^{1}$ Mahasiswa Pascasarjana PS. Silvikultur Tropika, Fakultas Kehutanan IPB

* Penulis korespondensi: e-mail: silferansti@gmail.com

${ }^{2}$ Staff Pengajar Dept. Silvikultur, Fakultas Kehutanan IPB
}

tergantung pada ketersediaan benih, misalnya dengan teknik perbanyakan secara vegetatif (stek pucuk ).

Beberapa penelitian pembiakan vegetatif stek pucuk dan inokulasi Fungi Mikoriza Arbuskula secara terpisah telah banyak dilakukan (Basir 2008), (Fitria 2015) dan Umam 2008). Metode tersebut memiliki banyak kelebihan dibandingkan metode pembiakan generatif yang umum digunakan saat ini. Metode pembiakan vegetatif lebih praktis karena tidak tergantung pada musim berbuah dan pada proses pengangkutan lebih murah (Sakai \& Subiakto 2007). Ketersediaan bibit gosale yang bermutu diperoleh melalui teknik pembibitan yang baik dengan cara membekali bibit dengan penggunaan Fungi Mikoriza Arbuskula. Menurut Scagel (2001), FMA pada stek pucuk berperan dalam menginisiasi pembentukan akar adventif, sehingga mampu mengubah arsitektur morfologi perakaran tanaman dengan cara mensintesa auksin yang dilepaskan di sekeliling pangkal tunas stek yang mempengaruhi perubahan-perubahan yang terlibat dalam pembentukan akar adventif yang diperantarai hormon.

FMA memiliki sifat obligat sehingga membutuhkan tanama inang. Penambahan tanaman Pueraria javanica dimaksudkan untuk mendukung perkembangan hidup FMA karena pada awal pertumbuhan stek gosale belum memiliki akar. Kajian mengenai respon pertumbuhan bibit gosale terhadap inokulasi FMA indigenous masih sangat terbatas, sehingga perlu dilakukan pengujian 
apakah FMA indigenous memiliki keefektifan pada pertumbuhan stek gosale atau tidak. Penelitian ini bertujuan untuk menguji efektivitas inokulasi FMA indigenous terhadap pertumbuhan stek gosale.

Manfaat penelitian ini adalah memberikan informasi mengenai inokulasi FMA pada stek gosale sehingga dapat menghasilkan pertumbuhan yang baik, terutama dalam pembibitan dan dalam rangka rehabilitasi dan reklamasi.

\section{METODE PENELITIAN}

\section{Waktu dan Tempat Penelitian}

Penelitian ini dilaksanakan pada Agustus 2016 sampai Mei 2017. Bibit dan contoh tanah diambil pada rhizosfer gosale yang tumbuh pada areal Hutan Rakyat Desa Kusumadehe dan Soakonora Kecamatan Jailolo, Halmahera Barat. FMA diidentifikasi di Laboratorium Silvikultur SEAMEO BIOTROP. Trapping FMA dan pembibitan gosale dilakukan di rumah kaca SEAMEO BIOTROP

\section{Prosedur Kerja}

\section{Pengambilan contoh tanah}

Contoh tanah diambil pada rhizosfer gosale sebanyak 500 g pada setiap lokasi. Pengambilan sampel tanah dilakukan dengan cara mengambil tanah bagian rhizosfer dibawah tegakan gosale dengan empat sisi berbeda. Tanah yang diambil berkisaran antara 0-20 cm dari permukaan tanah. Selanjutnya contoh tanah hasil komposit sebanyak $500 \mathrm{~g}$ dimasukan ke dalam kantong plastik yang diberi label (Nusantara et al. 2012).

\section{Isolasi dan karakterisasi tipe FMA}

Isolasi spora dari contoh tanah dilakukan dengan mengacu metode tuang saring dan dilanjutkan dengan modifikasi sentrifugasi dari Brundrett et al. (1996). FMA diidentifikasi dan dihitung jumlah spora.

\section{Penangkaran (Trapping) FMA}

Teknik penangkaran (Trapping) menggunakan metode Brundrett et al. (1996) dengan menggunakan pot-pot kultur kecil (150 g volume). Media tanam yang digunakan berupa campuran contoh tanah $50 \mathrm{~g}$ dan batuan zeolit berukuran 1-2 mm sebanyak $100 \mathrm{~g}$. Tanaman inang yang digunakan adalah Sorgum. Pemeliharaan kultur meliputi penyiraman, pemberian hara dan pengendalian hama secara manual. Larutan hara yang digunakan adalah Hyponex merah dengan konsentrasi $1 \mathrm{~g} / 2 \ell$ air. Pemberian larutan hara dilakukan setiap 2 minggu sebanyak $\pm 20 \mathrm{ml}$ tiap pot kultur. Pemanenan spora dilakukan setelah kultur berumur 4 bulan untuk mendapatkan spora-spora yang digunakan sebagai bahan inokulasi pada stek pucuk gosale.

\section{Persiapan media sapih}

Media untuk menyapih bibit stek adalah campuran tanah, pasir dan arang sekam (1:1:1). Sebelum dimasukkan ke dalam polybag, media diayak terlebih dahulu dan disterilisasi dengan cara pemanasan $120^{\circ} \mathrm{C}$ menggunakan drum selama 5 jam. Setelah itu media dimasukkan ke dalam polybag berukuran $15 \mathrm{~cm}$ x $15 \mathrm{~cm}$. Stek gosale disapih setelah media dibiarkan dalam keadaan lembab kurang lebih 1 minggu.

\section{Inokulasi dan pemeliharaan}

Tanaman gosale berasal dari Kabupaten Halmahera Barat. Stek gosale yang ditanam terlebih dahulu dioleskan dengan Rootone $f$ lalu diletakkan pada rumah sungkup dengan suhu $21-27^{\circ} \mathrm{C}$ dan kelembaban $80 \%$. Pemberian Rootone- $f$ sebagai perangsang akar berfungsi dalam pembentukan dan pertumbuhan bagian-bagian vegetatif tanaman yakni mendorong pemanjangan dan pembesaran sel akar, tunas dan batang (Wachjar et al. 1998). FMA sebanyak 30 spora diletakkan pada kertas saring ukuran $1 \times 0.5 \mathrm{~cm}$, diinokulasi ke lubang tanam untuk setiap polybag sesuai perlakuan. Inokulum FMA yang digunakan adalah dua tipe spora yang dominan tersedia

Tabel 1 Deskripsi FMA yang diisolasi dari tegakan gosale asal Halmahera Barat

\begin{tabular}{|c|c|c|}
\hline Tipe spora & Deskripsi morfologi & Asal \\
\hline \multicolumn{3}{|l|}{ Acaulospora sp. 2} \\
\hline & $\begin{array}{l}\text { Spora bulat, berwarna putih kekuningan, diberi melzer terjadi } \\
\text { perubahan warna pada bagian dalam dinding menjadi jingga, } \\
\text { memiliki saccule. }\end{array}$ & $\begin{array}{l}\text { gosale, } \\
\text { Halmahera } \\
\text { Barat }\end{array}$ \\
\hline \multicolumn{3}{|c|}{ Snora hulat herwarna collat permulan holus diheri molzer } \\
\hline & $\begin{array}{l}\text { Spora bulat, berwarna coklat, permukaan halus, diberi melzer } \\
\text { tidak terjadi perubahan warna. }\end{array}$ & $\begin{array}{l}\text { gosale, } \\
\text { Halmahera } \\
\text { Barat }\end{array}$ \\
\hline
\end{tabular}


setelah trapping seperti yang dideskripsikan pada Tabel 1. Stek dipelihara di rumah kaca dan diamati setiap dua minggu selama 3.5 bulan. Penyiraman dilakukan dua kali sehari pada pagi dan sore hari selain itu juga dilakukan pembersihan dari gulma.

\section{Variabel pengamatan}

Variabel yang diamati yaitu pertambahan tinggi bibit (cm), pertambahan diameter bibit $(\mathrm{mm})$, berat kering pucuk (BKP), berat kering akar (BKA), nisbah pucuk akar (NPA) dan kolonisasi FMA (\%).

\section{Rancangan percobaan}

Penelitian dilakukan di rumah kaca menggunakan rancangan acak lengkap (RAL) dengan perlakuan inokulasi spora FMA, terdiri dari:

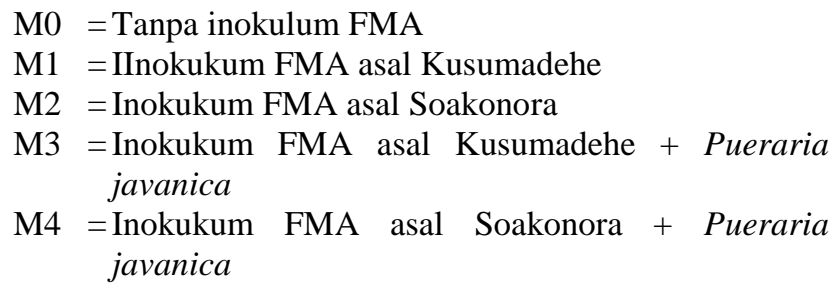

Masing-masing perlakuan diulang sebanyak 5 kali dan terdiri 4 unit sehingga terdapat 100 tanaman yang diamati. Data hasil dianalisis menggunakan sidik ragam program SAS 9.1. Jika perlakuan berpengaruh nyata dilakukan uji lanjut Duncan $5 \%$.

\section{HASIL DAN PEMBAHASAN}

Inokulasi FMA indigenous berpengaruh terhadap pertumbuhan stek gosale seperti yang ditunjukkan pada Tabel 2. Hasil analisis sidik ragam memperlihatkan pengaruh tersebut sangat nyata pada semua peubah yang diamati. Dari hasil tersebut maka dilakukan uji lanjut Duncan pada masing-masing peubah.

\section{Tinggi (cm) dan diameter tanaman (mm)}

Pertumbuhan tanaman diindikasikan dengan adanya pertambahan jumlah dan dimensi tanaman baik tinggi maupun diameter. Perlakuan inokulasi FMA indigenous terhadap pertambahan tinggi dan diameter tanaman stek pucuk gosale ditunjukkan seperti pada Gambar 1. Setiap jenis FMA indigenous yang diinokulasikan sesuai perlakuan memiliki pertambahan dimensi yang berbedabeda. Hasil uji lanjut Duncan memperlihatkan bahwa tertinggi untuk pertambahan tinggi adalah pada perlakuan M1 yang tidak berbeda dengan M2 (Gambar 1a). Perlakuan tertinggi pertambahan diameter juga pada perlakuan M1 dan M2. (Gambar 1b).

Gambar 1a menunjukkan bahwa inokulasi FMA asal Kusumadehe (M1) dan Soakonora (M2) sama-sama memberikan pertambahan tinggi stek gosale yang lebih baik kecuali dengan penambahan tanaman inang Pueraria javanica (M3 dan M4). Hal tersebut dapat terjadi karena inokulum FMA yang di inokulasikan merupakan FMA indigen yang diperoleh dari habitat alam yang memiliki adaptasi tinggi. Mansur (2002) mengemukakan bahwa isolasi FMA dari tanaman lokal akan lebih efektif untuk meningkatkan pertumbuhan tanaman lokal tersebut dari pada digunakan isolat dari luar daerah tersebut. Pertumbuhan terendah ditunjukkan pada perlakuan inokulasi FMA pada stek yang ditanam bersama Pueraria javanica (M3 dan M4). Kelambatan pertumbuhan salah

Tabel 2 Rekapitulasi hasil analisis sidik ragam pengaruh inokulasi FMA terhadap peubah yang diamati

\begin{tabular}{|c|c|c|c|c|c|}
\hline \multirow{2}{*}{ Peubah } & \multicolumn{5}{|c|}{ Perlakuan } \\
\hline & M0 & M1 & M2 & M3 & M4 \\
\hline \multicolumn{6}{|l|}{ Pertambahan tinggi $(\mathrm{cm})$} \\
\hline 2 MST & $0.5 \mathrm{tn}$ & $0.4 \mathrm{tn}$ & $0.5 \mathrm{tn}$ & $0.4 \mathrm{tn}$ & $0.3 \mathrm{tn}$ \\
\hline $4 \mathrm{MST}$ & $1.4 * *$ & $1.6 * *$ & $1.6 * *$ & $1.0 * *$ & $0.8 * *$ \\
\hline $6 \mathrm{MST}$ & $2.6 * *$ & $2.8 * *$ & $2.7 * *$ & $1.9 * *$ & $1.5 * *$ \\
\hline $8 \mathrm{MST}$ & $3.8 * *$ & $4.9 * *$ & $4.5 * *$ & $2.8 * *$ & $2.3 * *$ \\
\hline $10 \mathrm{MST}$ & $5.3 * *$ & $7.4 * *$ & $7.4 * *$ & $3.5 * *$ & $3.2 * *$ \\
\hline $12 \mathrm{MST}$ & $6.9 * *$ & $10.2 * *$ & $9.6 * *$ & $5.3 * *$ & $3.8 * *$ \\
\hline $14 \mathrm{MST}$ & $9.2 * *$ & $13.3 * *$ & $12.3 * *$ & $6.6 * *$ & $5.0 * *$ \\
\hline \multicolumn{6}{|c|}{ Pertambahan diameter $(\mathrm{mm})$} \\
\hline $2 \mathrm{MST}$ & $0.18 \mathrm{tn}$ & $0.20 \mathrm{tn}$ & $0.16 \mathrm{tn}$ & $0.12 \mathrm{tn}$ & $0.14 \mathrm{tn}$ \\
\hline $4 \mathrm{MST}$ & $0.28 \mathrm{tn}$ & $0.34 \mathrm{tn}$ & $0.34 \mathrm{tn}$ & $0.26 \mathrm{tn}$ & $0.28 \mathrm{tn}$ \\
\hline $6 \mathrm{MST}$ & $0.50 \mathrm{tn}$ & $0.56 \mathrm{tn}$ & $0.50 \mathrm{tn}$ & $0.42 \mathrm{tn}$ & $0.40 \mathrm{tn}$ \\
\hline $8 \mathrm{MST}$ & $0.70 \mathrm{tn}$ & $0.76 \mathrm{tn}$ & $0.78 \mathrm{tn}$ & $0.54 \mathrm{tn}$ & $0.54 \mathrm{tn}$ \\
\hline $10 \mathrm{MST}$ & $0.90 * *$ & $1.10 * *$ & $1.10 * *$ & $0.72 * *$ & $0.74 * *$ \\
\hline $12 \mathrm{MST}$ & $1.20 * *$ & $1.54 * *$ & $1.54 * *$ & $1.06 * *$ & $0.90 * *$ \\
\hline $14 \mathrm{MST}$ & $1.48 * *$ & $1.88 * *$ & $1.90 * *$ & $1.24 * *$ & $1.08 * *$ \\
\hline Berat Kering Pucuk (g) & $1.12 * *$ & $1.64 * *$ & $1.58 * *$ & $0.38 * *$ & $0.35 * *$ \\
\hline Berat Kering Akar $(\mathrm{g})$ & $0.42 * *$ & $0.55 * *$ & $0.53 * *$ & $0.16 * *$ & $0.15 * *$ \\
\hline Kolonisasi FMA (\%) & $3.33 * *$ & $53.56 * *$ & $61.33 * *$ & $24.22 * *$ & $15.56 * *$ \\
\hline
\end{tabular}


satunya disebabkan oleh gagalnya simbiose perakaran bibit dengan FMA. Hambatan pertumbuhan itu bisa disebabkan karena persaingan antara tanaman gosale dan Pueraria javanica dalam memperoleh nutrisi. Selain itu diduga karena Pueraria javanica bersifat merambat dan membelit (Reksohadiprodjo 1981) sehingga menghambat petumbuhan stek gosale.

Peningkatan diameter sangat dipengaruhi oleh fotosintat dan $\mathrm{H}_{2} \mathrm{O}$. Hormon auksin yang terkandung pada Rootone- $f$ juga dapat memacu pertumbuhan jaringan pembuluh dan mendorong pembelahan sel pada kambium pembuluh sehingga mendukung pertumbuhan diameter batang.

\section{Biomassa pucuk dan akar tanaman (g)}

Hasil uji Duncan biomassa tanaman disajikan pada Tabel 3. Hasil ini memperlihatkan bahwa perlakuan M1 dan M2 pada peubah berat kering pucuk (BKP) dan berat kering akar (BKA) merupakan perlakuan terbaik dibandingkan dengan perlakuan lainnya. Persentase peningkatan BKP dan BKA stek gosale perlakuan M1 terhadap kontrol (M0) dan terendah (M4) secara berturutturut sebesar $37.81 \%$ dan $368.58 \%$, pada peubah BKA sebesar $30.95 \%$ dan $266.67 \%$. Persentase peningkatan

Tabel 3 Pengaruh inokulasi FMA indigenous terhadap biomassa BKP dan BKA stek gosale umur 14 minggu setelah tanam

\begin{tabular}{lcccc}
\hline \multirow{1}{*}{ Inokulasi FMA } & \multicolumn{4}{c}{ Biomassa } \\
& \multicolumn{2}{c}{ BKP } & \multicolumn{3}{c}{ BKA } \\
\hline M0 (tanpa FMA) & 1.19 & $\mathrm{~b}$ & 0.42 & $\mathrm{~b}$ \\
M1 (Inokulum asal & 1.64 & $\mathrm{a}$ & 0.55 & $\mathrm{a}$ \\
$\begin{array}{l}\text { Kusumadehe) } \\
\text { M2 (Inokulum asal Soakonora) }\end{array}$ & 1.58 & $\mathrm{a}$ & 0.53 & $\mathrm{a}$ \\
M3 (Inokulum asal & 0.38 & $\mathrm{c}$ & 0.16 & $\mathrm{c}$ \\
$\begin{array}{l}\text { Kusumadehe + Pueraria } \\
\text { javanica }\end{array}$ & & & & \\
$\begin{array}{l}\text { M4 (Inokulum asal Soakonora } \\
+ \text { Pueraria javanica }\end{array}$ & 0.35 & $\mathrm{c}$ & 0.15 & $\mathrm{c}$ \\
\hline
\end{tabular}

Keterangan: angka-angka yang diikuti oleh huruf yang sama pada kolom yang sama menunjukkan tidak berbeda nyata pada taraf $\alpha 5 \%$
BKP stek gosale perlakuan M2 sebesar $32.77 \%$ terhadap kontrol (M0), sebesar $351.43 \%$ terhadap perlakuan (M4), pada peubah BKA sebesar $26.19 \%$ dan $253.33 \%$.

Berat kering tanaman merupakan indikator yang umum digunakan untuk mengetahui baik atau tidaknya pertumbuhan bibit, karena berat kering tanaman dapat menggambarkan efisiensi proses fisiologis di dalam tanaman yaitu proses fotosintesis, respirasi, translokasi dan penyerapan air serta mineral (Handayani 2009). Konsistensi nilai tertinggi yang ditunjukkan oleh perlakuan M1 dan nilai terendah yang ditunjukkan pada perlakuan M4 sejalan dengan hasil pada peubah pertambahan tinggi dan pertambahan diameter diameter. Hal ini sesuai pernyataan Karepesina (2007) bahwa semakin tinggi kemampuan tanaman menyerap unsur hara, maka semakin meningkat pula biomassa tanaman karena terjadi aktivitas fotosintesis yang berlangsung lebih efisien. Biomassa tanaman juga dipengaruhi oleh peranan FMA dalam menyerap unsur hara terutama fosfat, unsur hara lain, air, serta karbohidrat (Smith \& Read 2008).

\section{Nisbah pucuk akar}

Nisbah pucuk akar menggambarkan keseimbangan antara pertumbuhan bagian diatas bibit dan bagian akarnya. Nisbah pucuk akar (NPA) merupakan faktor penting dalam pertumbuhan tanaman yang mencerminkan perbandingan antara proses transpirasi dan luasan fotosintesis dari tanaman dengan kemampuan penyerapan

Tabel 4 Nisbah pucuk akar (NPA) terhadap inokulasi FMA pada stek gosale umur 14 minggu setelah tanam

\begin{tabular}{lc}
\hline \multicolumn{1}{c}{ Perlakuan Inokulasi FMA } & NP \\
& A \\
\hline M0 (tanpa FMA) & 2.68 \\
M1 (Inokulum asal Kusumadehe) & 3.00 \\
M2 (Inokulum asal Soakonora) & 2.96 \\
M3 (Inokulum asal Kusumadehe + Pueraria & \\
javanica & 2.34 \\
M4 (Inokulum asal Soakonora + Pueraria & \\
javanica & 2.37 \\
\hline
\end{tabular}

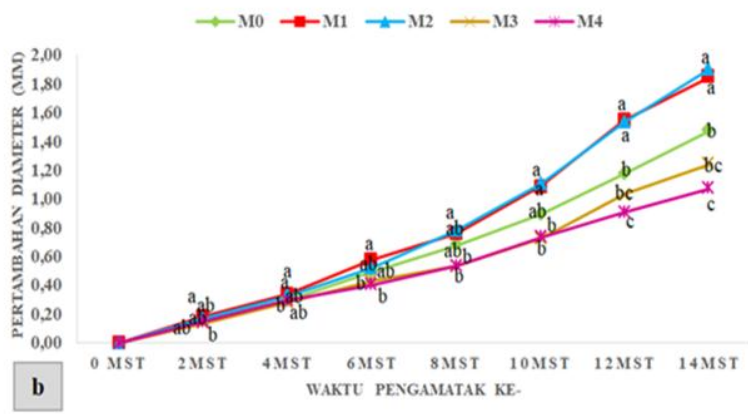

Gambar 1 Pengaruh inokulasi FMA terhadap pertambahan tinggi (a) dan diameter $\quad$ (b) stek pucuk gosale umur 0 sampai 14 minggu setelah tanam. Huruf yang sama menunjukkan tidak berbeda nyata pada taraf $\alpha 5 \%$ 
air dan mineral (Setyaningsih et al. 2000). Bibit dinilai siap dan layak tanam apabila memiliki nilai NPA berkisar 2-5 (Mindawati \& Yusnita 2005) seperti bibit stek gosale pada penelitian ini (Tabel 4).

\section{Kolonisasi FMA}

Semua jenis FMA baik yang berasal dari tegakan gosale asal Kusumadehe dan Soakonora yang diuji dapat menginfeksi perakaran stek gosale. Gambar 2 menunjukkan persentase kolonisasi FMA tanaman stek gosale.

Pengamatan kolonisasi FMA dilakukan dengan cara pewarnaan akar mengacu pada metode Philips dan Hayman (1970). Hasil penelitian menunjukkan bahwa berdasarkan kategori yang dibuat oleh Rajapakse dan Miller (1992) yang dimodifikasi (Nusantara et al. 2012) kolonisasi FMA tergolong tinggi pada perlakuan inokulum FMA tanpa Pueraria Javanica (M1 dan M2), tergolong rendah pada perlakuan inokulum FMA dengan Pueraria javanica (M3 dan M4) dan tergolong sangat rendah terhadap kontrol (M0). Hasil uji lanjut duncan menunjukkan kemampuan FMA untuk menginfeksi akar dan menghasilkan kolonisasi berbeda pada setiap perlakuan. Persentase kolonisasi FMA tertinggi pada perlakuan M2 dengan nilai nilai $61.33 \%$ dengan persen kenaikan sebesar $1741.74 \%$ terhadap kontrol (M0) membentuk struktur yang lengkap pada jaringan akar mulai dari hifa, vesikula, arbuskula dan spora.

Respon yang dihasilkan akibat pemberian FMA terhadap semua parameter berbeda-beda karena efektivitas setiap FMA yang berbeda dalam menginfeksi akar stek gosale. Perbedaan keefektifan yang terjadi atas setiap perlakuan inokulum FMA dengan Pueraria javanica dan tanpa Pueraria javanica disebabkan adanya perbedaan kemampuan dari setiap FMA dalam bersimbiosis dengan akar stek. Persentase kolonisasi menggambarkan adanya simbiosis dan kesesuaian antara tanaman inang dan FMA tetapi tidak mutlak sebagai indikator terhadap tinggi rendahnya pertumbuhan tanaman inang (Allen 2001).

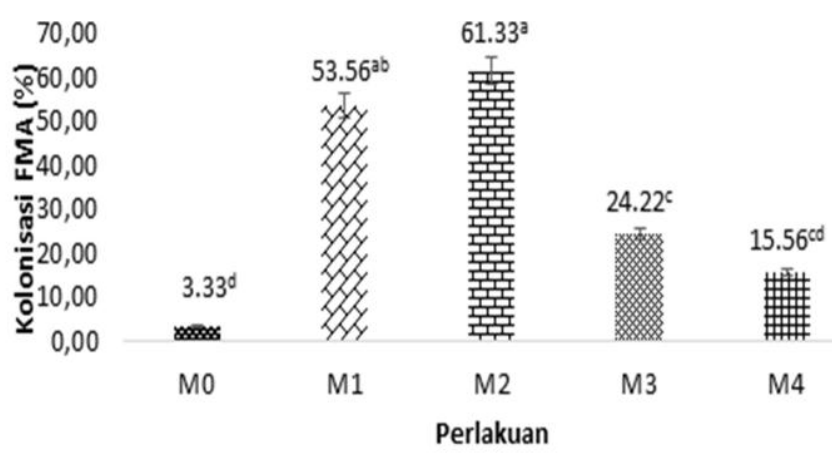

Gambar 2 Diagram kolonisasi FMA pada akar stek gosale umur 14 MST

\section{SIMPULAN DAN SARAN}

\section{Simpulan}

Pemberian inokulum FMA indigenous efektif terhadap pertumbuhan stek pucuk gosale. Secara umum perlakuan inokulum FMA asal Kusumadehe dan Soakonora tanpa penambahan tanaman inang Pueraria javanica merupakan perlakuan tertinggi pada setiap peubah yang diamati yakni pada pertambahan tinggi, pertambahan diameter, berat kering pucuk, berat kering akar, nisbah pucuk akar, indeks mutu bibit, dan persentase kolonisasi FMA.

\section{Saran}

Disarankan agar melakukan stek pucuk untuk perbanyakan bibit dan untuk meningkatkan pertumbuhan disarankan untuk memproduksi bibit stek gosale bermikoriza dengan FMA indigenous.

\section{DAFTAR PUSTAKA}

Allen MF. 2001. Modeling arbuscular mycorrhizal infection: is percent infection an appropriate variable. Mycorrhiza J. 10:255-258.

Balai Perbenihan Tanaman Hutan Maluku dan Papua, 2010. Laporan Identifikasi dan Inventarisasi Sumber Daya Genetik. Ambon

Basir. 2008. Pengaruh Rootone-f dan Media Terhadap Pertumbuhan Stek Pucuk Ulin (Eusideroxylon zwageri T et B). Jurnal Hutan Tropis Borneo No. 22 Maret 2008

Brundrett MC. Bougherr N, Dells B, Grove T, Malajczuk N. 1996. Working with mycorrhizas in forestry and agriculture. Canberra (AU): Australian Centre for International Agricultural Reserach.

Fitria FN. 2015. Pembiakan Saninten (Castanopsis argentea (Blume) A.DC.) Melalui Stek Pucuk Dengan Zat Pengatur Tumbuh Komersial [skripsi]. Bogor (ID): Institut Pertanian Bogor

Handayani M. 2009. Pengaruh dosis pupuk NPK dan kompos terhadap pertumbuhan bibit salam (Eugenia polyantha Wight) [skripsi]. Bogot (ID): Institut Pertanian Bogor.

Karepesina S. 2007. Keanekaragaman Fungi Mikoriza Arbuskula dari Bawah Tegakan Jati Ambon (Tectona grandis Linn.f.) dan Potensi Pemanfaatannya [Tesis]. Bogor (ID): Institut Pertanian Bogor.

Mansur I. 2000. Diversity of rhizobia nodulating the tree legumes Acacia magium and Paraseranthes falcataria and their interaction with arbuscular mycorrizal fungi in young seedling. $\mathrm{PhD}$ Dissertation, University of Kent at Canterbury, Kent, Inggris.

Mindawati N, Yusnita S. 2005. Pengaruh Macam Media terhadap Pertumbuhan Semai Acacia mangium Willd. Jurnal Penelitian Hutan dan Konservasi Alam 
2(1): 53-59. Pusat Penelitian dan Pengembangan Hutan dan Konservasi Alam. Bogor.

Nusantara AD, Bertham YH, Mansur I. 2012. Bekerja dengan Fungi Mikoriza Arbuskula. Bogor (ID): SEAMEO BIOTROP.

Phillips JM, Hayman DS. 1970. Improved procedures for clearing roots and staining parasitic and vesiculararbuscular mychorizal fungi for rapid assessment of infection. Transact Brit Mycol Soc. 55:158-161.

Rajapakse S, Miller Jr JC.1992. Methods for studying vesicular-arbuscular mycorrhizal root colonization and related root physical properties. Methods Microbiol. 24:302-316

Reksohadiprodjo S. 1981. Produksi Tanaman Hijauan Makanan Ternak Tropik. Fakultas Peternakan. Universitas Gadjah Mada. Yogyakarta.

Sakai C, Subiakto C. 2007. Pedoman pembuatan stek jenis-jenis dipterokarpa dengan KOFFCO System. Kerjasama Badan Litbang Kehutanan, Komatsu dan JICA, Pusat Penelitian dan Pengembangan Hutan dan Konservasi Alam. Bogor (ID): Kementrian Kehutanan
Scagel CF. 2001. Stimulation of adventitious rooting on cuttings from woody perennial plants by exprosure to inoculum of ericoid and arbuscular mycorrhizal fungi. International unfcrence on myutrrhizu.s. Adclaidc-Australia. http://www.arserin. gov/ars/Pac WesUCorval lis/herl/SCAC ELWEB/ PRESEN TAI9N/| CO M\%2Shandout\%20 2001 .pdf.

Setyaningsih L, Munawar Y, Turjaman M. 2000. Efektifitas Cendawan Mikoriza Arbusula dan Pupuk NPK terhadap Pertumbuhan Bitti. Prosiding Seminar Nasional Mikoriza I. hlm 192-201.

Smith SE, Read DJ. 2008. Mycorrhizal symbiosis. Third ed. New York (US):Academic Press.

Wachjar A, Setiadi Y, Hastuti TR. 1998. Pengaruh dosis inokulum cendawan mikoriza arbuskula (Gigaspora Rosea) dan pupuk nitrogen terhadap pertumbuhan bibit kopi robusta (Coffea canephora Pierre ex Foehner). Bul. Agron 26(2): 1-7.

Umam MD. 2008. Studi Aplikasi Fungi Mikoriza Arbuskula Pada Stek Pucuk Jati Muna (Tectona grandis Linn.F) di Persemaian Akar Telanjang [tesis]. Bogor (ID): Institut Pertanian Bogor. 